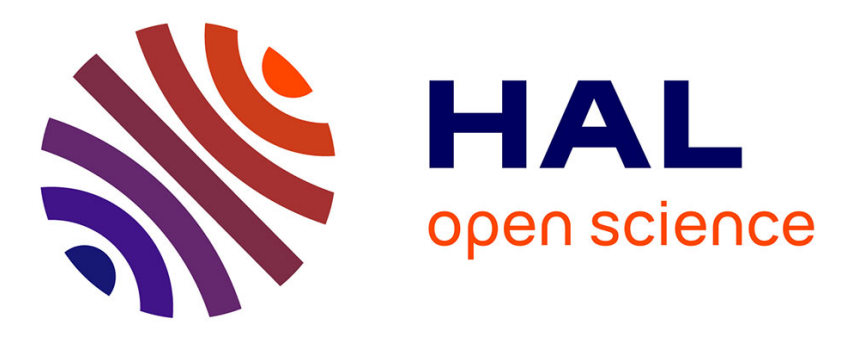

\title{
European transmission grid expansion as a flexibility option in a scenario of large scale variable renewable energies integration
}

Stéphane Allard, Silvana Mima, Vincent Debusschere, Tuan Tran Quoc, Patrick Criqui, Nouredine Hadjsaid

\section{To cite this version:}

Stéphane Allard, Silvana Mima, Vincent Debusschere, Tuan Tran Quoc, Patrick Criqui, et al.. European transmission grid expansion as a flexibility option in a scenario of large scale variable renewable energies integration. Energy Economics, 2020, Available online 6 March 2020, pp.104733. 10.1016/j.eneco.2020.104733 . hal-02502378

\section{HAL Id: hal-02502378 \\ https://hal.science/hal-02502378}

Submitted on 20 Jan 2022

HAL is a multi-disciplinary open access archive for the deposit and dissemination of scientific research documents, whether they are published or not. The documents may come from teaching and research institutions in France or abroad, or from public or private research centers.
L'archive ouverte pluridisciplinaire HAL, est destinée au dépôt et à la diffusion de documents scientifiques de niveau recherche, publiés ou non, émanant des établissements d'enseignement et de recherche français ou étrangers, des laboratoires publics ou privés. 


\title{
European transmission grid expansion as a flexibility option in a scenario of
}

\section{large scale variable renewable energies integration}

\author{
Stéphane Allard ${ }^{a b c}$, Silvana Mima ${ }^{b}$, Vincent Debusschere ${ }^{a}$, Tuan Tran Quoc $^{c}$, Patrick $^{\text {Criqui }}{ }^{b}$ \\ and Nouredine Hadjsaid ${ }^{a}$ \\ ${ }^{a}$ Univ. Grenoble Alpes, CNRS, Grenoble INP ${ }^{l}$, G2Elab, 38000 Grenoble, France \\ ${ }^{b}$ GAEL, CNRS, Grenoble INP $P^{l}$, INRA, Univ. Grenoble Alpes, 38000, Grenoble, France \\ ${ }^{c}$ CEA - INES, Univ. Grenoble Alpes, 73370 Le Bourget-du-Lac, France
}

\begin{abstract}
This paper presents a new power sector module, called EUTGRID, which is coupled with the long-term energy model POLES to deliver a suitable framework for considering grid aspects in energy modelling allowing for more distinct analysis of energy technology development and energy policy. It includes a mechanism of investment in transmission grids based on nodal prices together with a DC-load flow and a more detailed description of the European transmission grid. The methodology goes beyond "conventional" energy systems modelling, where the electricity grid is usually represented as a copper plate.
\end{abstract}

The results show that within a climate policy scenario, the grid investment needs reach $454 \mathrm{~b} \$$ for $2010-2080$ as regions with high share of VREs require new interconnections. The role of the transmission grid in reducing variable system costs and VREs curtailment is also assessed. Delaying the investments may result in non-distributed energy and the need of more back-up carbon technologies.

\footnotetext{
${ }^{1}$ Institute of Engineering Univ. Grenoble Alpes
} 
Keywords: transmission grid investment mechanism, long-term energy model, variable renewable energy integration, unit commitment and dispatch, (DC) load flow, Europe

\section{Introduction}

Nowadays, fighting climate changes urges governments to implement efficient climate energy policies and large-scale integration of variable renewable energies (VREs) to strongly reduce $\mathrm{CO}_{2}$ emissions(Commission renewable energy 2017; IRENA 2018). However, the power system was developed as a vertical system with an important and centralized electricity production (nuclear, coal etc.) together with an extensive transmission grid which transports electricity to the final consumer. This particular architecture helped the system to be robust and reliable. On the opposite, VREs production is intermittent and less predictable. In a context of high share of VREs, it becomes more difficult for other electricity power plants to compensate the residual load. As a result, the system needs to be more flexible than before.

To achieve the security and the reliability of the power system, new options of flexibilities have emerged such as Demand Side Management, storage technologies and VREs curtailment. However, using all these options may not be enough to integrate a high share of VREs. Indeed, renewable energies potentials are unevenly distributed in Europe but also within a country(Velte, Magro, and Jiménez 2010). Therefore, if VREs distribution follows its potential, electricity generation will highly increase in some regions and thus, it will increase power flows exchanges with the neighbouring regions. Hence, the existing transmission grid would face congestion and the options of flexibilities will not be sufficient to alleviate these bottlenecks. As a result, reinforcement and extension of interconnections within Europe may play a crucial role to match VREs production and consumption. 
These new situations lead to question the transmission grid requirements in case of large scale integration of VREs and how its evolving architecture will affect the others flexibility options. To answer these questions, a new module called EUTGRID (EUropean - Transmission Grid Investment and Dispatch) has been developed and dynamically coupled with the long-term energy model POLES ${ }^{2}$ (Criqui and Mima 2012).

To maintain the stability of the system, the production must be equal to the consumption (including losses). This main objective leads to two sort of management which are linked: shortterm power management and long-term energy management of the power system.

Short-term management corresponds to the operation of the power system within an hour using local infrastructure (congestions, voltage management) (Kunz 2013). On the opposite, longterm management aims at localizing future bottlenecks at European level in 4 to 10 years.

The objective is that optimal and adequate long-term investments are made so that short-term operations do not face problems. As a result, in our model, we use the hypothesis that shortterm management will help to make long-term investments through congestion signals. This method differs from planning studies which need future demand projections and then perform short-term management to localize future bottlenecks.

The paper is organized as follows: in section 1, the characteristics and specifications of different models dealing with the electric grid are specified. Then, in section 2, the module EUTGRID is described. Section 3 provides enriched insights related to the grid issues in the framework of high integration of VREs. Finally, conclusions and further research are proposed in the section 4.

\footnotetext{
${ }^{2}$ Prospective Outlook for Long-term Energy Systems
} 


\section{Transmission capacity planning}

Because short-term and long-term management have different objectives and issues, one can observe two different families of modelling: (1) Power grid models and (2) Long-term energy models.

\subsection{Power grid models}

Technical modelling aims at describing with precision the operation of the power system, at given time horizons. The electric grid is depicted with great details and parameters such as voltage, active and reactive power, frequency are analysed. The questions answered concern for example the stability of a grid in case of massive renewable integration in operational studies, or the management of storage and new flexibilities levers in a smart grid context. Usually these studies only cover a portion of a national grid.

These models can also be used for planning studies on a larger scale (Europe, USA). However, the level of details is reduced for simplicity. A good example in this field is Antares (Doquet et al. 2008). It is a sequential Monte-Carlo system simulator developed by the French transmission system operator, RTE. It uses Monte-Carlo method to simulate many different meteorological years on an hourly basis in order to assess the economic benefits of different projects (development of wind farms, grid expansion). Antares covers Europe with about 500 nodes and it is used to run many tests to localize future bottlenecks. Then, it can decide future grid investments based on 3 indicators: the energy not served (ENS), extra spillage (production curtailment) and thermal dispatch. The hypothesis is that reinforcements between 2 zones with important differences between the values of indicators will have a greater impact. These set of reinforcements are then assessed by comparing the cost savings and the cost of the investments (e-Highway 2050 2015). 
A similar model, Elmod (Leuthold, Weigt, and von Hirschhausen 2012), was developed in order to analyse congestion management and investments decisions. It covers Europe with over 2000 nodes and optimizes the operation of the system for one year on an hourly basis. In a first version (Jeske et al. 2007), the grid investment mechanism is based on nodal prices to detect congestions. The decision to invest is made if the annualized investment costs is lower than the welfare increase caused by the reinforcement option. In a more recent version (Egerer, Gerbaulet, and Lorenz 2016), the objective function to minimize is equal to the sum of all investments costs and variable system costs. The final set of reinforcement is found when the objective function stops decreasing.

\subsection{Long-term energy models}

While technical models need to make strong assumptions on how consumption and generation capacities will evolve, long-term energy models help to get a global overview of all energy sectors and also the interactions between them. Different families of energy modelling tools exist which can be classified in top-down and bottom-up models (Van Beeck 2000). "Bottomup" models are mainly dealing with VREs integration, grid and storage operations but they need a higher level of detail in representing flexibility options. Very few long-term energy models actually implement electricity dispatch and decision investments in the transmission grid (Després et al. 2015; Pietzcker et al. 2017). Indeed, in many models such as POTENCIA (Mantzos, Ciampi Stancova, and Institute for Prospective Technological Studies 2016) and WEM-IEA (IEA 2016), there is a linear relation between investments in VREs capacities and investments in upgrade or extension of the transmission grid: for each MW of VREs installed, they assume an increase of transmission grid investments. POLES model (Criqui and Mima 2012; Criqui et al. 2015) has been improved through a coupling with a dispatch module EUCAD 
(Després et al. 2017). It aims at optimising the power system operations while the investments in the transmission grid are decided by POLES depending of the usage of the interconnections. ${ }^{3}$

\subsection{Characteristics needed for a transmission capacity planning module}

The description of the two different families of modelling shows that each family lacks some key features which are implemented in the other one. For this reason, some long-term energy models and technical models have been coupled either in a one way method such as between Elmod model and PRIMES (E3MLab 2017; Egerer, Gerbaulet, and Lorenz 2016) ${ }^{4}$; or in a dynamic process like between POLES and EUCAD (Després et al. 2017) ${ }^{5}$. This latter linking greatly improves the yearly investments made in long-term simulations. Therefore, the transmission grid capacity planning module coupled with POLES will be based on a similar coupling used by EUCAD. Thus, it will make dynamic transmission grid investment based on different scenarios provided by POLES.

In technical models, the number of nodes covering the transmission grid is much more important than the one in long-term energy models (see Annex 1). As a result, increasing the number of nodes seems to be an important point to add in the module together with a more realistic power flow calculation. Indeed, these power flows will help detecting and relieving the congestions through a grid investment mechanism. To achieve this, nodal prices can be implemented and used to calculate congestion costs between two clusters ${ }^{6}$.

In a transmission capacity planning module, the decision to reinforce or to add a line is a key parameter. When a line is being reinforced, it reduces the transmission costs and it has an impact on the neighbouring cluster. This impact can be positive by reducing VREs curtailment or non-

\footnotetext{
3 Annex 1 summarizes different features of the technical and long-term energy models specifically for the transmission grid representation.

${ }^{4}$ Elmod uses the results from PRIMES as main inputs for its analysis on a specific year

${ }^{5}$ POLES and EUCAD exchanges pieces of information every simulated year

${ }^{6}$ In this article, clusters or nodes are used indistinctly
} 
distributed energy to the consumers. But it can be negative and increase the total system cost as congestion appears in other clusters. Therefore, each reinforcement project should be economically assessed before being accepted.

In this study, a coupling of two different tools is being presented which synthetizes the different key characteristics needed: POLES long-term energy model is being used for providing climate energy scenarios for the world and EUTGRID allows a detailed representation of European power sector by including EUCAD and a transmission capacity planning module.

\section{EUTGRID, a module for transmission capacity planning}

\subsection{General description}

In order to capture the impact of the large-scale integration of VREs into the transmission grid, EUTGRID model has been developed with 4 main objectives:

1. Implementing a more detailed transmission grid

2. Detecting congestions within the grid

3. Implementing a mechanism for dynamic investments in the transmission grid

4. Coupling with POLES, the long-term energy model.

EUTGRID incorporates a unit commitment and dispatch tool that minimises the total operating costs of the system on a 24-hour basis under different constraints: supply at each node must be equal to the demand, transmission grid power flows must respect the maximum thermal line capacities, ramping capabilities, minimum and maximum generation capacities by technology.

A more detailed description of equations used and implemented in EUTGRID can be found in Annex 2. 


\subsubsection{Modelling the pan-european transmission grid}

The European project "e-Highway 2050" has developed a clustering method to reduce the grid representation model from the current 10000 nodes to 96 nodes (Anderski et al. 2014).

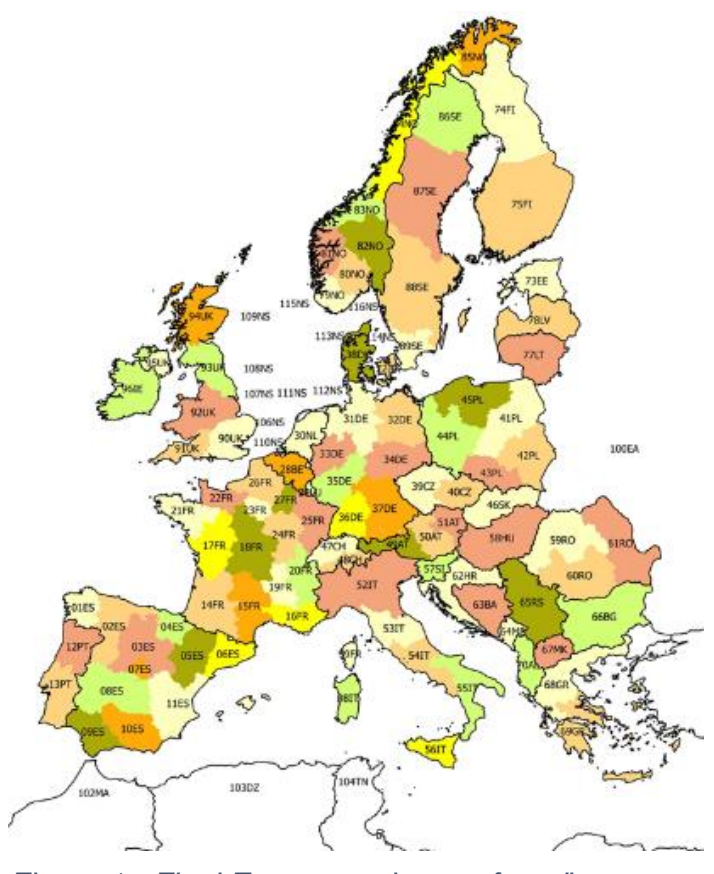

Figure 1 - Final European clusters from "eHIGHWAY 2050"

EUTGRID implements "e-HIGHWAY 2050" clustering (see Figure 1) constructing the corresponding database for these 87 nodes $^{7}$. In EUTGRID, the European transmission grid covers 24 countries and it does not include Baltic and western Balkans countries.

\subsubsection{Detecting congestions within the grid}

The transmission grid must follow physical laws known as Kirchhoff's and Ohm's laws. Because of these laws, the path followed by the electricity is often different from the path chosen with an optimal method such as in the "transport" model ${ }^{8}$ (Manzo 2009). The resulting "unwanted" path is called loop flows and this phenomenon appears more frequently in case of

\footnotetext{
${ }^{7}$ It is important to note that the clusters which were proposed do not cover two countries and also that transmission system operators were consulted on this clustering.

${ }^{8}$ Power flows are only restricted by line capacities. Therefore, it can be seen as commercial contracts but it does not represent the grid reality.
} 
unplanned production such as VREs and it can heavily stress the grid (Skånlund et al. 2013). This can cause congestion within the grid. Therefore, a linearized model called "DC load flow" 9 is implemented in EUTGRID to calculate the power flows taking into account grid characteristics. The equations can be found in Annex 2 .

In order to detect these congestions, nodal prices are used as a signal. Indeed, a high price means that in order to satisfy the next MW of demand it is not possible to import from the congested line but power plants must be re-dispatched (Kunz 2013). As a result, it has been assumed that if the difference between two nodal prices is important, there is a congestion (Phillips 2004; Dietrich et al. 2005).

\subsubsection{Implementing a mechanism for investments in the transmission grid}

With the implementation of a DC model, it is not possible to directly optimize the operation of the power system and grid investments. Indeed, the resulting set of equations becomes nonlinear (Schaber 2014) and it is very time-consuming to solve.

A method to address this problem is to iterate through the most congested lines and then increase the capacity of the transmission lines as done in Elmod model (Leuthold, Weigt, and von Hirschhausen 2012; Jeske et al. 2007). In EUTGRID it is implemented but with some key improvements:

- Grid capacity increase can be chosen between HVAC (High Voltage Alternating Current) and HVDC (High Voltage Direct Current) technologies

- Grid costs are multiplied by a coefficient which depends of the typology of the cluster (urban, rural and mountain) (Vafeas, Pagano, and Peirano 2014, 1)

\footnotetext{
${ }^{9}$ The linearization of AC load flow is called « DC load flow » because the resulting equations look like direct current flows.
} 
- Grid investments are only allowed if the annualized reduction of the total costs covers the annualized investments in less than the return on investment (ROI), which in our case is assumed to be ten years, see equation (1) (RTE 2016).

$$
R O I=\frac{I}{\left(O_{B}-O_{A}\right) * \frac{\eta}{1-(1+\eta)^{-\alpha}}} \leq 10
$$

where:

$I$ is the total cost for investing in HVAC or HVDC lines [k\$];

$O_{A}$ is the total cost of the system after grid reinforcement $[\mathrm{k} \$]$;

$O_{B}$ is the total cost of the system before grid reinforcement $[\mathrm{k} \$]$;

$\eta$ is the discount rate (set to $8 \%$ rounded value of weighted capital cost calculated by the French Regulatory Commission of Energy (Commission de régulation de l'énergie 2013) ); $\alpha$ is the technical life-time of HVAC/HVDC(set to 40 years)

In addition, $I$ is calculated by using equation (2) :

$$
I=C_{C} * \frac{\eta}{1-(1+\eta)^{-\alpha}}+\delta * d * C_{L} * \frac{\eta}{1-(1+\eta)^{-\alpha}}
$$

where:

$C_{C}$ is the investments costs for HVAC transformer or for a converter station [k\$];

$\delta$ is a coefficient whose value depends of the typology of the cluster: it is more expensive to install a transmission line in a mountainous region than in a rural one (Vafeas, Pagano, and Peirano 2014)

$d$ is the distance between 2 clusters $[\mathrm{km}]$

$C_{L}$ is the total cost of a line which adds investments costs and capacity costs [k\$]

The costs are taken from (Couckut et al. 2015). 
The mechanism of investment goes through different steps which are described in Figure 2.

The algorithm stops when ten consecutives on-shore projects are rejected. This criterion is set to reduce computations and at the same time insure that enough on-shore and off-shore connections are considered.

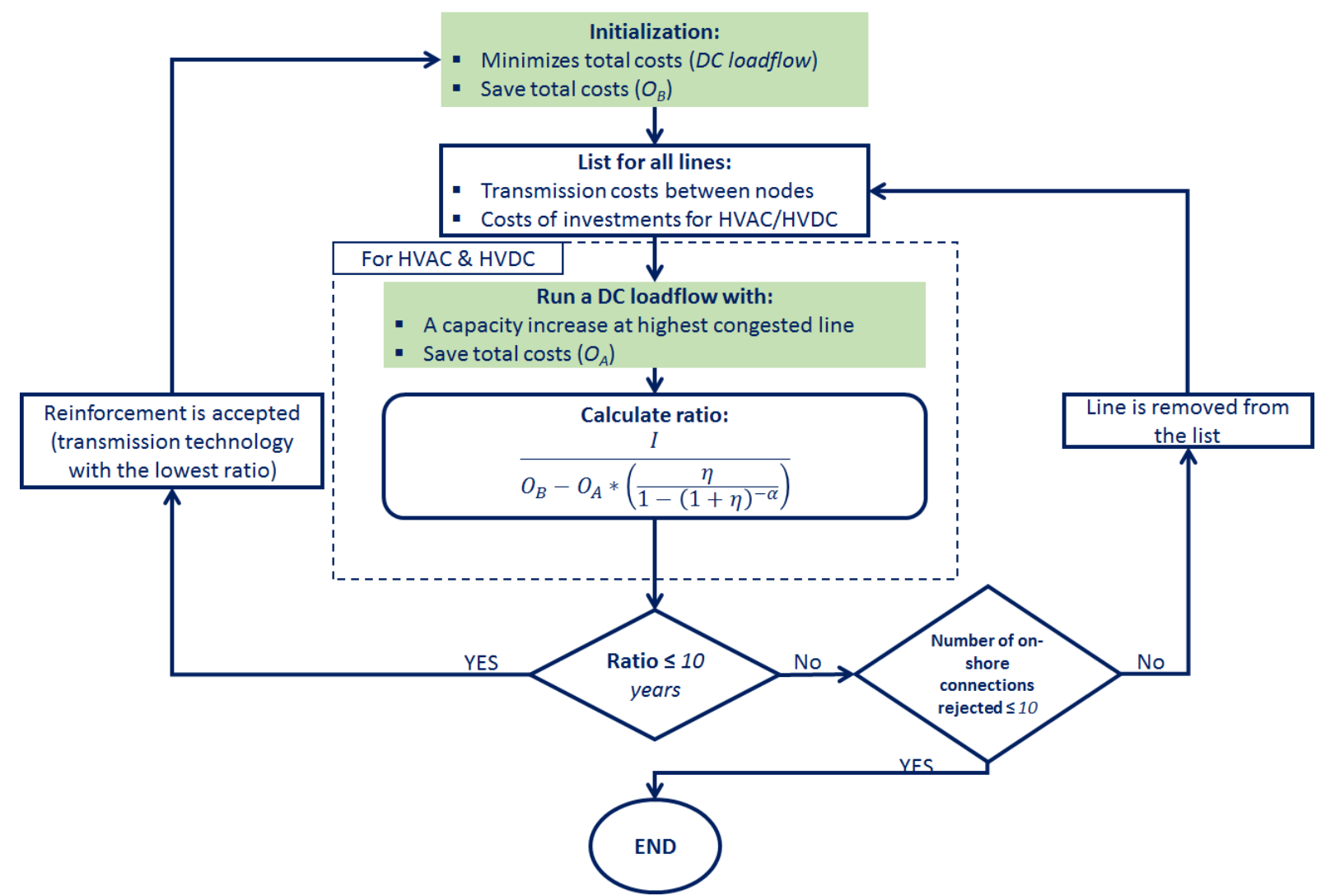

Figure 2-Diagram describing the grid investment mechanism

\subsubsection{Coupling with the long term energy model, POLES}

EUTGRID provides in-depth details on the operations of the power sector and it is coupled with POLES, the long-term energy model. The IRENA report (IRENA 2017) underlines that such a "coupling" approach can translate a system's needs for flexibility in operation (a focus of production cost models) into decisions around investment (a focus of generation expansion models)." This connection works as an exchange of information between POLES and EUTGRID for every simulated year. 
The coupling can be described as follows: at year N, POLES provides the state of the power system with installed capacities, electricity demand at state level. These pieces of information are used as input data for EUTGRID which computes the operation of the power sector. Then, the output data are send back to POLES which can make the investments decisions and move to the next year. This is shown in Figure 3.

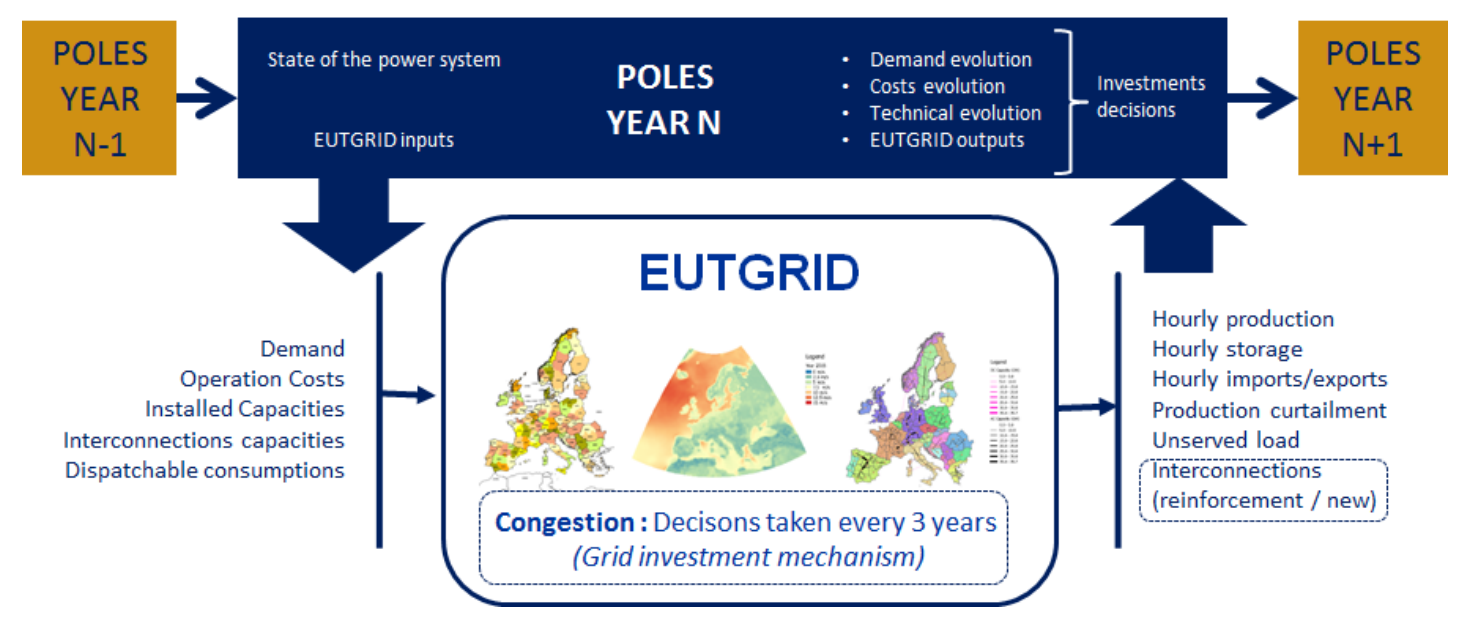

Figure 3 -Diagram of the coupling between POLES and EUTGRID

Once the power dispatch over Europe has been computed, EUTGRID is able to decide new investments in the transmission grid. However, with the fast and large-scale integration of VREs capacities, a double phenomenon must be taken into account: location of future bottlenecks need to be anticipated while at the same time, actual congestions must be resolved as installed capacities differ from expectations. The expected capacities are determined by POLES with myopic simulations.

To capture these two types of planning, the mechanism consists of a 3-year rolling window. At the beginning of this 3-year period, transmission grid investments are calculated based on expected installed capacities at 10 years: it is the anticipation planning. Then at the end of the 3-year period, the investments needs are determined using actual installed power plant capacities in order to solve congestions. 


\subsection{Input data}

\subsubsection{Typical VREs production days}

Because of their variability, VREs need to be well represented into the model so that hourly, daily and seasonal variations are taken into account (Després 2015). Although it would be most precise to run EUTGRID with hourly historical production data for each cluster, it requires extensive data and computation time.

Hourly production for each cluster do not exist as most of them do not represent actual administrative regions. Therefore, capacity factors were calculated using wind speed and solar radiation data from reanalysis database (it is a database which standardizes and correct past meteorological observations at a very detailed precision) (Saha et al. 2011). Hourly solar and wind production at cluster level were determined using the methods described in (Bett and Thornton 2016).

Finally in order to simplify the number of days to compute and at the same time keep a good representation of renewable production variabilities, the clustering method introduced in (Nahmmacher et al. 2014) was applied to get six typical VREs production days for summer and for winter (12 days in total) (see Figure 4 for a description of the method)

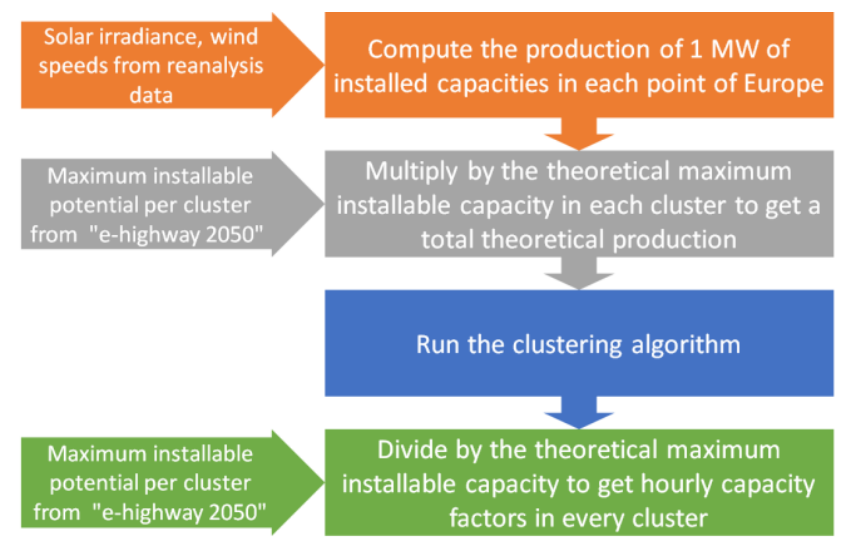

Figure 4- Diagram showing how to choose and calculate the typical days (adapted from (Després 2015)) 


\subsubsection{Distributing generation capacities and demand for all European countries}

As previously mentioned, EUTGRID has implemented a more detailed transmission grid with 87 nodes based on the project "e-highway 2050" (Anderski et al. 2014). At the same time, the coupling with POLES provides input data which are available only per country (i.e. national

installed capacities, national demand). Because of this situation, it is needed to build the corresponding database for these 87 nodes for the supply, the demand and the grid. POLES country data for electricity demand and supply has been split into clusters based on different distribution keys for VREs and conventional capacities and electricity consumption: population, wind speed, solar irradiation, thermal and hydro installed capacities and available land by cluster.

- Conventional and hydro capacities

As pointed out by operators in (Bruninx et al. 2014), future power plants are mainly built next to already installed ones as social acceptance is higher and it costs less for them. For these reasons, actual capacities are considered as a proxy for the distribution of conventional and hydro capacities in EUTGRID. Data were retrieved from public sources such as Enipedia and Global energy observatory databases (Global Energy Observatory 2016; Enipedia 2016).

\section{- VREs capacities}

Installation of VREs depends strongly on social acceptance and geopolitics issues which are difficult to take into account in a model. For this reason, simplified proxies which consist of linear distribution keys using weighted capacity factors were used for solar and wind technologies (Bruninx et al. 2014). These distributions are linear combinations of population, maximum potential, and available land for building. These coefficients were determined through fitting with historic data (source: government databases. If, for a country, historic data at a local level did not exist, the same coefficients as its neighbour were used.). 
- Electricity consumption

Electricity consumption depends of different factors such as GDP or population as implemented in POLES. However, in EUTGRID, for simplification, population distribution was used as a proxy for electricity consumption (Q. Zhou and Bialek 2005). It has been validated with the electricity consumption of all French regions in 2014 and their corresponding population and GDP (sources: RTE and INSEE).

\subsubsection{Evolution of the transmission grid from 2012 to 2030}

\section{- Initial conditions}

An aggregated transmission grid which connects the different clusters is needed to be able to start the simulations. It should have the following characteristics: maximum capacities and impedance values for power flow calculations. In (Anderski et al. 2014), this work has been done by using 2012 grid data and TYNDP 2014 document (ENTSO-E 2014a). However, the results for 2012 are not available for confidential reasons (Grisey 2016).

In this context, different datasets exist that describe the pan-European transmission grid such as TYNDP $2014^{10}$ (ENTSO-E 2014b). This version is very useful for calculating power flows but it lacks the coordinates of its nodes. To fill this gap, Bialek made publicly available a dataset based on ENTSO-E map (Hutcheon and Bialek 2013).

As a result, the extraction of transmission grid characteristics from available maps was done at the borders between clusters as in (Qiong Zhou 2003). It was assumed that within a cluster there is no congestion. For each line, the following characteristics were retrieved: voltage $(110 \mathrm{kV}$, $220 \mathrm{kV}$, and $380 \mathrm{kV})$, number of circuits per line and type of line (AC or DC). Based on these data, it is possible to get their thermal transmission limit (Egerer et al. 2014).

\footnotetext{
${ }^{10}$ Many other datasets are available and a list which is regularly maintained can be found at : http://wiki.openmodinitiative.org/wiki/Transmission_network_datasets
} 
Figure 5 shows the result of the aggregation method for the 2012 European transmission grid.

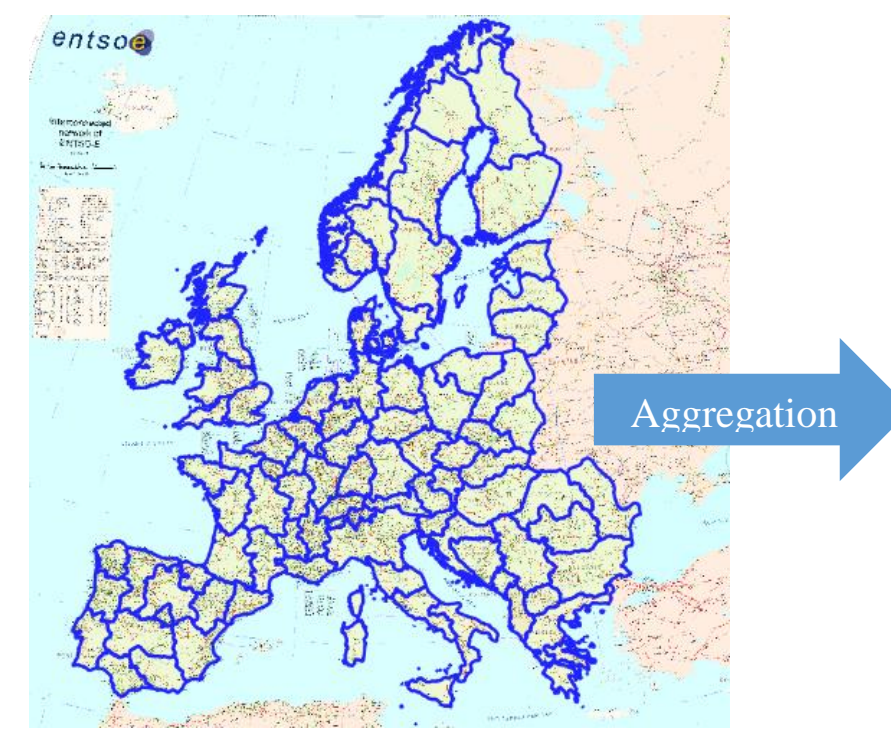

Figure 5- (a) Georeferencing ENTSO-E map 2012 HVDC) in 2012

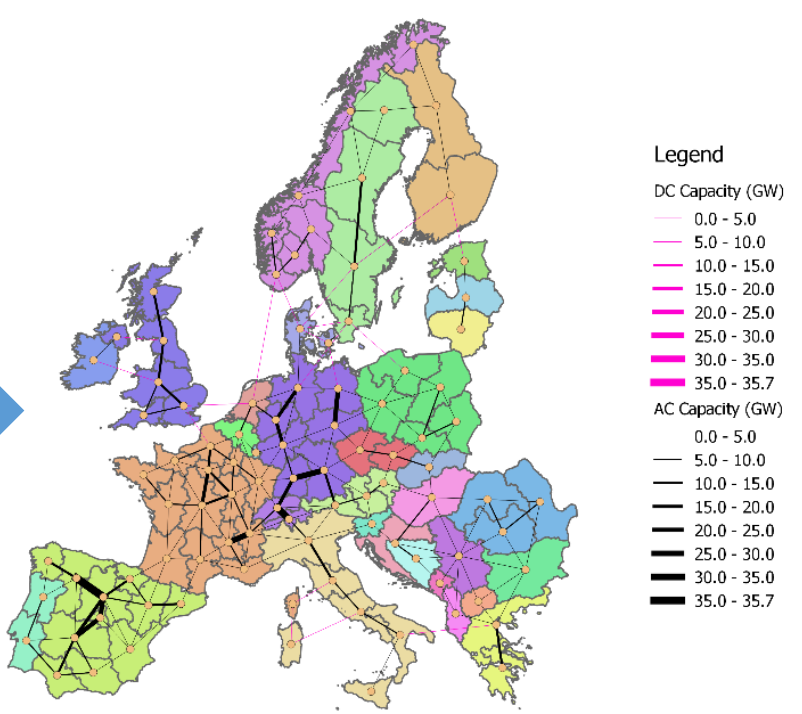

(b) Aggregated transmission grid (HVAC \&

- Evolution of the transmission grid towards 2030

The evolution of both the demand and the capacities installed within Europe modifies the power flows and can put some pressure in some regions. For this reason, ENTSOE produces every two years since 2010 a report which identifies future bottlenecks and investments needed to relieve them. Hence the European project "e-Highway 2050" used the report TYNDP published in 2014 (ENTSO-E 2014a) in order to identify the new investments for each clusters in 2030 and made them publicly available(Anderski et al. 2014). However, the evolution of the transmission grid from 2012 up to 2030 is missing. Therefore, the table of HVDC projects from TYNDP 2014 was used in this work with their expected commissioned time. For AC cable investments, a linear approximation of grid capacity and circuits was used from 2012 up to 2030 for simplification.

In Annex 3, the transmission grid capacity module implemented in EUTGRID has been validated by comparing its results for 2 scenarios during 2010-2030 and ENTSO-E's investments. 


\section{Model results and discussion}

To question the role of the transmission grid in large-scale VREs situations, two main scenarios are set up from 2000 to 2080: a scenario with no carbon tax ("Ref - Grid") and a scenario with a climate energy policy starting in 2012 ("Clim - Grid"). In the second scenario, the carbon tax increases costs production of the most carbonized technologies. As a result, the system is pushed to invest in cleaner technologies and particularly, in VREs capacities. The effects of the policy are visible in Figure 6 where installed solar and wind capacities for Europe are plotted for the two scenarios. Indeed, in "Clim - Grid", 1.1 TW of solar and 0.9 TW of wind capacities are added which are to be compared with $0.95 \mathrm{TW}$ of solar and $0.6 \mathrm{TW}$ of wind capacities in the "Ref - Grid".

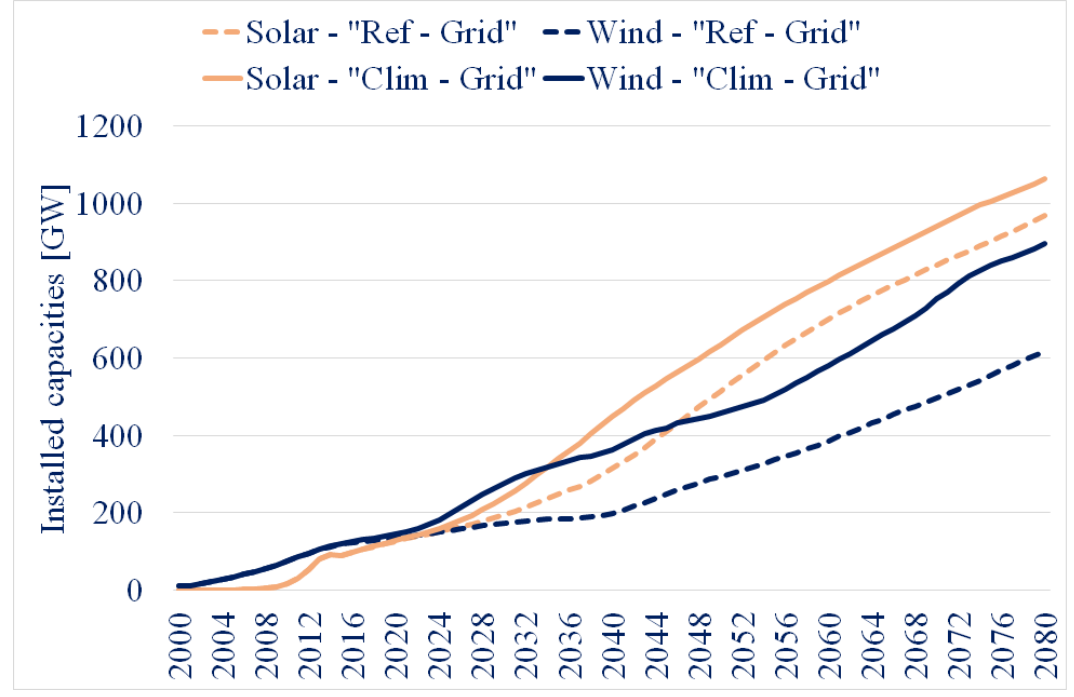

Figure 6 - Installed VREs capacities in Europe in GW

\subsection{Transmission grid investments in the "reference" scenario versus a " $2{ }^{\circ} \mathrm{C}$ climate policy" scenario}

In both scenarios, VREs production increases its share in the energy mix but the evolution differs. In "Clim - Grid", it starts from 5\% in 2010, it reaches 22\% in 2030, $32 \%$ in 2050 and up to $41 \%$ in 2080 as shown in Table 1. On the opposite, in "Ref - Grid", VREs share grows slower: it is equal to $14 \%$ in $2030,23 \%$ in 2050 and $37 \%$ in 2080 . This difference in growth has an important impact on power flows and therefore the apparition of congestions. 


\begin{tabular}{|c|c|c|c|c|}
\hline \multicolumn{2}{|r|}{ "Clim - Grid" scenario } & $2010-2030$ & $2030-2050$ & $2050-2080$ \\
\hline \multicolumn{2}{|r|}{ Production VREs [\%] } & {$[5 \% ; 22 \%]$} & {$[22 \% ; 32 \%]$} & [32\%;41\%] \\
\hline \multirow{5}{*}{ 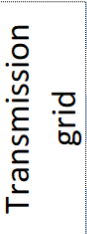 } & HVAC added [GW] & 202 & 68 & 92 \\
\hline & HVDC added [GW] & 42 & 70 & 53 \\
\hline & Line length added [000km] & 61 & 37 & 41 \\
\hline & Grid added [TWkm] & 97 & 72 & 77 \\
\hline & Total grid investment [b\$] & 180 & 136 & 139 \\
\hline
\end{tabular}

\begin{tabular}{|c|c|c|c|c|}
\hline \multicolumn{2}{|r|}{ "Ref - Grid" scenario } & $2010-2030$ & $2030-2050$ & $2050-2080$ \\
\hline \multicolumn{2}{|r|}{ Production VREs [\%] } & {$[5 \% ; 14 \%]$} & {$[14 \% ; 23 \%]$} & {$[23 \% ; 37 \%]$} \\
\hline \multirow{5}{*}{ 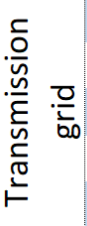 } & HVAC added [GW] & 202 & 58 & 49 \\
\hline & HVDC added [GW] & 42 & 41 & 41 \\
\hline & Line length added [000km] & 61 & 24 & 26 \\
\hline & Grid added [TWkm] & 97 & 46 & 45 \\
\hline & Total grid investment [b\$] & 180 & 87 & 83 \\
\hline
\end{tabular}

Table 1 - Comparison data between "Reference scenario" and "2 ${ }^{\circ} \mathrm{C}$ - Climate energy policy scenario"

In "Clim - Grid" scenario, large capacities of VREs are installed at fast pace in areas such as North Sea or Spain. As a result, the energy produced creates congestions around these areas and thus, transmission grid needs to be reinforced or even extended in order to benefit from this carbon-free energy. Transmission grid must be strengthened in terms of capacity with $68 \mathrm{GW}$ of HVAC and $70 \mathrm{GW}$ of HVDC in 2030-2050 (92 GW of HVAC and $53 \mathrm{GW}$ of HVDC for 2050 - 2080). Figure 7 shows the evolution of the European transmission grid investments for each period. One can observe that the regions with a high renewable potential are far from consumption areas which means important needs to connect them: 37 thousands kilometres of lines are added between 2030 and 2050 and 41 thousands kilometres between 2050 and 2080 . All these needs represent a total grid investment of $136 \mathrm{~b} \$$ for $2030-2050$ and $139 \mathrm{~b} \$$ for 20502080. For the period 2010-2030, EUTGRID includes the investments decided by ENTSO-E. It can be noticed that the total grid investment is in the same range as for the next periods. However, the projects considered by ENTSO-E take into many other characteristics such as social acceptance and technical and economic studies (the projects can even be modified or delayed). These reasons can explain the differences in terms of transmission grid capacity added and length of lines added. 
On the opposite, in "Ref- Grid" scenario, investments mainly concern conventional capacities as there is no carbon tax which could help to promote investments in VREs. As a result, share of VREs is kept at low level. Because these conventional capacities are located in regions with an already robust transmission grid, the needs for reinforcement are lower. Hence, for the period $2030-2050$, the newly installed transmission grid capacity is lower than in "Clim - Grid" with $58 \mathrm{GW}$ of HVAC and $41 \mathrm{GW}$ of HVDC (for $2050-2080,49 \mathrm{GW}$ of HVAC and $41 \mathrm{GW}$ of HVDC). Similarly, the needs to connect far regions diminish with only 24 thousand kilometres of lines added during $2030-2050$ and 26 thousand kilometres during $2050-2030$. Finally, the total grid investments reaches only 87 b\$ for 2030 - 2050 (-36\% compare to "Clim-Grid") and 83 b\$ for 2050 - 2080 (-40\% compare to "Clim-Grid").

To further compare the two scenarios and better understand the needs for reinforcing the transmission grid, a usual parameter can be introduced which is the product of the distance between two nodes and the capacity of the reinforcement (in TWkm): interconnections which are highly reinforced but are close to each other can therefore be compared with interconnections which are far but have been less reinforced. Hence, for $2030-2050$, these investments represent $72 \mathrm{TWkm}$ of new transmission lines for the "Clim - Grid" scenario while
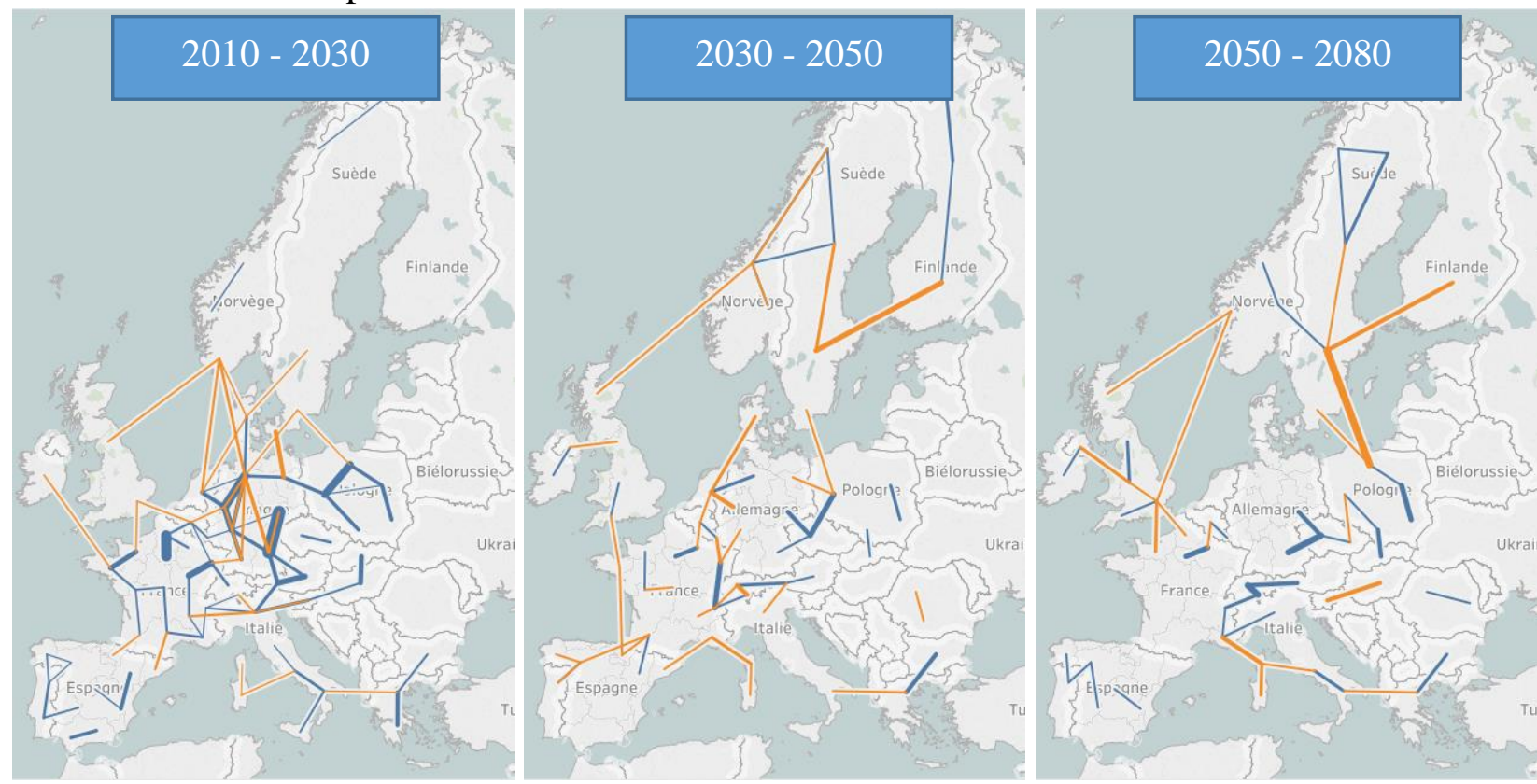

Capacity 
it reaches only $46 \mathrm{TWkm}$ in the "Ref - Grid" scenario. It confirms the conclusions that with a fast evolution of VREs share, transmission grid need to be reinforced to allow bigger power flows but also to connect far regions to match production and consumption.

\subsection{Impacts of grid investments: in depth analysis}

The two scenarios presented in section 3.1 show that the needs of the transmission grid increase when large scale integration of VREs is supported but the effects of these investments should be better evaluated. For this purpose, 3 sub-scenarios are studied and are based on a $" 2^{\circ} \mathrm{C}$ climate energy policy" scenario:

(1) "Clim - Copper": there are no restriction on power exchanges. This is a common hypothesis in long-term energy models.

(2) "Clim - Grid": there is a coupling between EUTGRID and POLES together with the grid mechanism investment.

(3) "Clim - Grid Delays": grid investments are stopped after 2030. It has been assumed that investments decided by ENTSO-E are already established.

When comparing the first two sub-scenarios, conclusions can be drawn on how a simple modelling ("Clim - Copper") can affect the results. On the opposite, the last two sub-scenarios will highlight the benefits of transmission grid investments.

Investing in the transmission grid has the major advantage to avoid a huge rise in variable costs as the share of VREs increases as shown in Figure 8. Indeed, if the transmission grid is not expanded or reinforced (“Clim - Grid Delays”), non-distributed energy (NDE) appears. It occurs when TSOs cannot import enough energy and are forced to limit load demand. Therefore, NDE is very expensive and highly unwanted. Hence, in "Clim - Grid Delays" scenario, at $40 \%$ share of VREs, variable costs reach almost 200\$/MWh. In the scenario where transmission grid is not a constraint ("Clim - Copper"), variable costs are lower but still 
increases as VREs share raises (from 20\$/MWh to 40\$/MWh). Finally, in "Clim - Grid", the variable costs reach a peak of $80 \$ / \mathrm{MWh}$ for $30 \%$ VREs and then diminishes to reach 40\$/MWh.

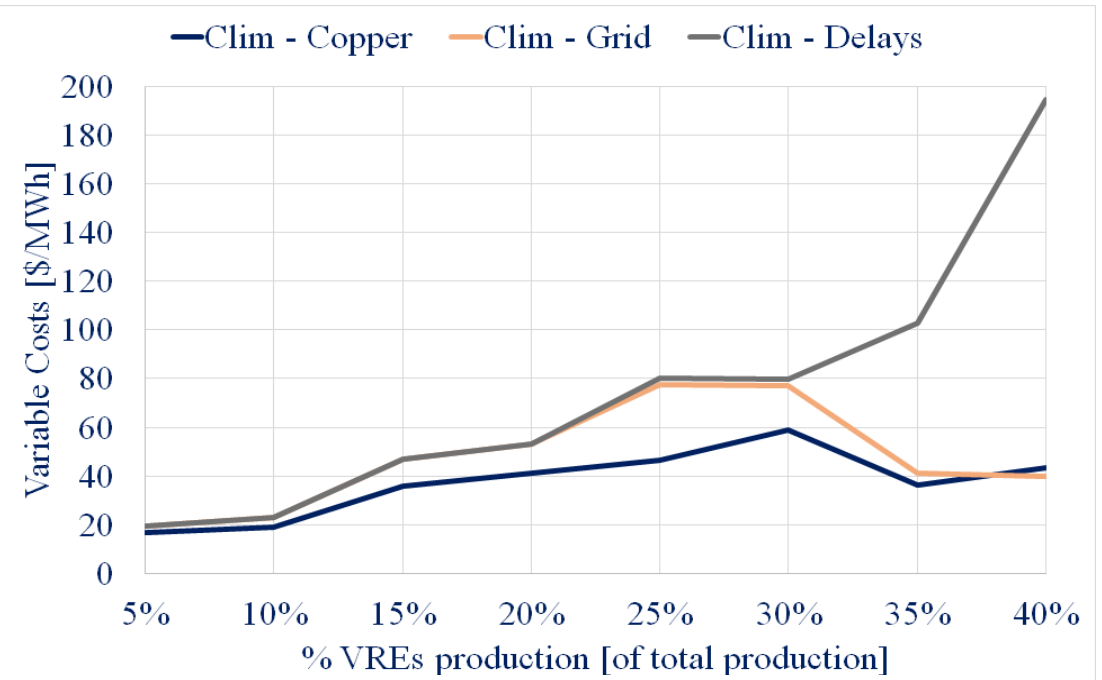

Figure 8- Total variable costs in Europe

The differences in costs underlines the fact that transmission grid is an important parameter to take into account in a model.

The evolution of variable costs shows that transmission grid has an impact on the production of power plants. This is particularly relevant when considering installed capacities and equivalent full load hours ${ }^{11}$ for back-up technologies (gas, coal and oil) depending of VREs integration (refer to Figure 9). In all sub-scenarios, gas power plants are the most installed ones while coal and oil decrease as more VREs are installed: gas power plants are very flexible and

\footnotetext{
${ }^{11}$ Equivalent full load hours represent the number of hours the power plants would have run at full capacity over a year.
} 


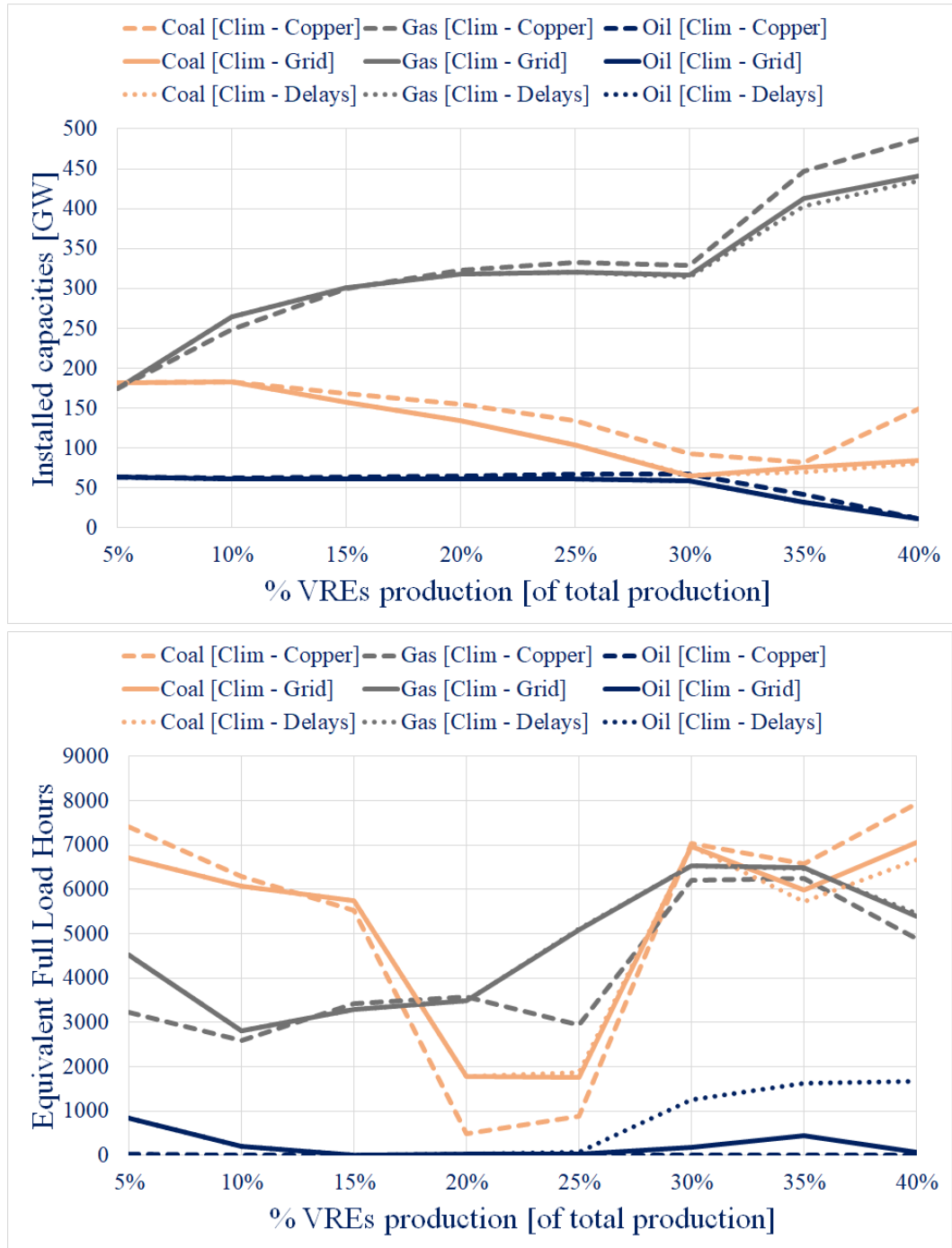

Figure 9- (a) Installed capacities and (b) equivalent full load hours for different scenarios

are cheaper compare to other power plants. Hence, with no restriction on exchanges ("Clim Copper"), gas is even more installed to benefit from these characteristics.

In the same time, it can be observed that gas increases also its equivalent full load hours as VREs share increases. On the opposite, coal shrinks up to 2000 hours for the "Clim - Grid" scenario when VREs' production covers $20-25 \%$ of the total production and then gets back to 7000 hours. This highlights the effect of the climate energy policy: the sudden increase of the carbon value makes coal less used and then with new investments in cleaner technologies, the variable costs are reduced. In a copper plate scenario, this phenomenon is even more visible. 
The effects for generation from oil power plants are easy to read as it has a high carbon-content: in a copper plate scenario, oil is never called as polluting technologies become very expensive. However, in the "Clim - Grid" scenario, between 30 and $40 \%$ of VREs integration, its equivalent full hours reaches around 700 hours. This is due to the restrictions from transmission grid and is confirmed by the results from the "Clim - Grid Delays" sub-scenario. Indeed, its equivalent full hours reaches up to 1700 hours which means that because of congestions, oil is

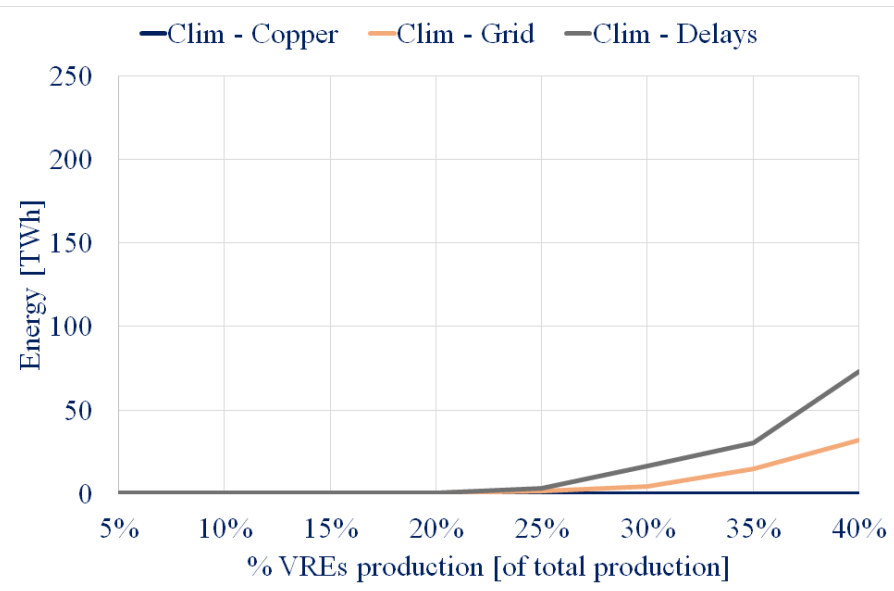

Figure 10 - Maximum VREs curtailment

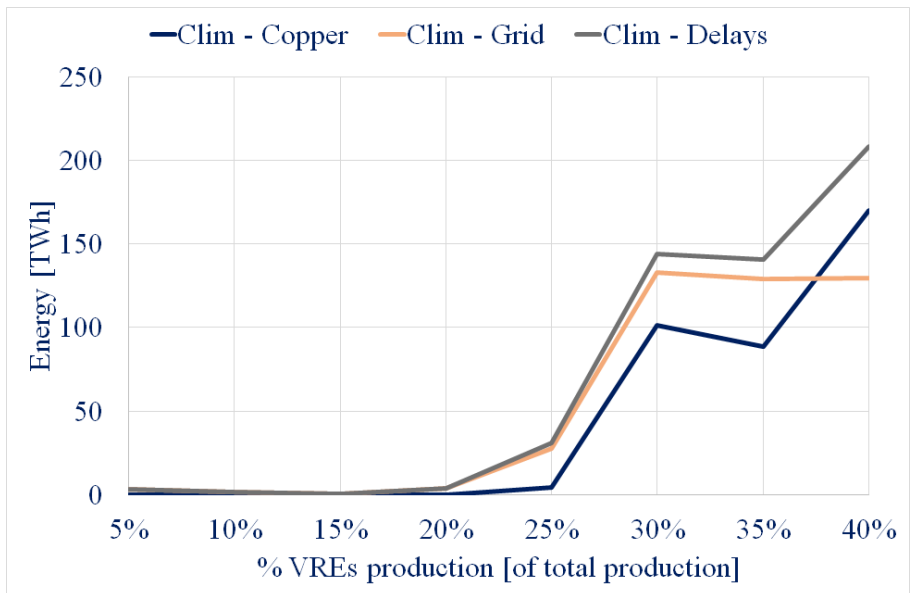

Figure 11 - Maximum energy produced from storage

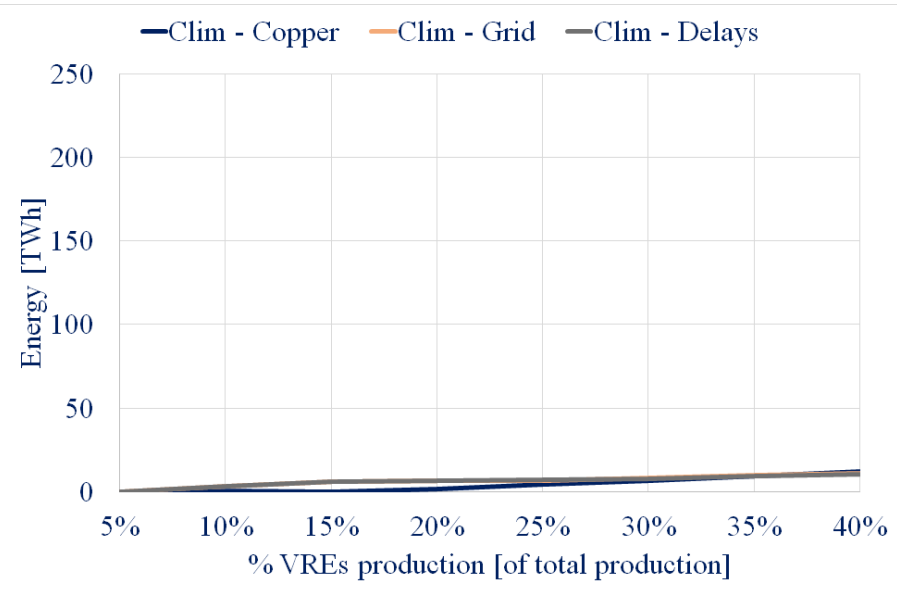

Figure 12 - Maximum energy shifted by demand response

used as a last option. The very last option being to stop supplying demand (NDE).

Transmission grid does not affect only conventional power plants management but also other flexibilities options which are also used for equalizing production and consumption. Indeed, VREs production does not follow consumption (the solar peak power is at noon while the peak load is in the evening) and it is sometimes needed to curtail this exceeding production. 
Similarly, it can be useful to shift load from peak hour to off-peak hours: it is called demand response. Finally, storage production can be used to add flexibility to the system: production is stored when needed and given back to the grid when necessary. These options can be analysed through three parameters: (1) VREs total curtailment (see Figure 10), (2) total energy production from storage technologies (see Figure 11), (3) total energy shifted by demand response means (see Figure 12).

In a copper plate scenario ("Clim - Copper"), VREs are not curtailed, on the contrary to the others sub-scenarios where power transmission has limits: when no grid investments are delayed (“Clim - Grid Delays"), curtailment increases much more as more VREs are integrated. With grid investments (“Clim - Grid"), curtailment is being reduced but not eliminated. Indeed, the benefits of cutting down VREs are not covered by the costs of upgrading the grid.

Concerning the second parameter, it can be observed that even with no restriction on electricity exportations, storage needs raise with the integration of VREs. However, with a real grid, these needs are greater and with no development, energy from production technologies reaches 200TWh. The same conclusions can be drawn for demand response. However, demand response has limitations as well. In this work, it reduces the load during an hour and then there is an increase of one third for the next hour (rebound effect) with the rest of the energy being dispatched later (Després 2015). These constraints limit its uses and in the end, demand response reaches its maximum potential with $10 \mathrm{TWh}$ activated at $40 \%$ VREs production.

\section{Conclusions}

In a context of large scale integration of VREs, their intermittent production and their uneven location weaken the power system stability. Hence, new flexibility options such as demand response, storage or VRE curtailments are gradually introduced. However, they are limited in terms of power and energy and it will not suffice to prevent congestions within the transmission 
grid. Therefore, to reduce congestions and improve the grid operation we evaluated the transmission grid's reinforcement and its influence on other flexibility options through a new European dedicated transmission grid module (EUTGRID) coupled with the long-term energy model POLES. This methodology is a significant progress in global energy system models as it allows realistic calculations of power flows and of transmission grid infrastructure requirements. These investments result from the competition between HVAC and HVDC technologies.

The results show that in a scenario with a climate policy of type $2^{\circ} \mathrm{C}$, VREs shares increase particularly in regions with high renewable potential such as Spain or North Sea. Hence, these regions need to reinforce and extend their interconnections with their neighbours. Adequate transmission grid investments in "Clim-Grid" scenario reduce the use of VREs curtailment, of storage and of demand response. While in case of delayed grid investments "Clim - Grid Delays", the electricity system needs more flexibility option and it is even forced to reduce the consumption.

In the same time, the growth of decentralized VREs production impact more and more the distribution grids implying not only congestions but also more variability of voltages. This relationship will be an interesting issue for further research. 
Annex 1: Characteristics of different models studied concerning their representation of the grid

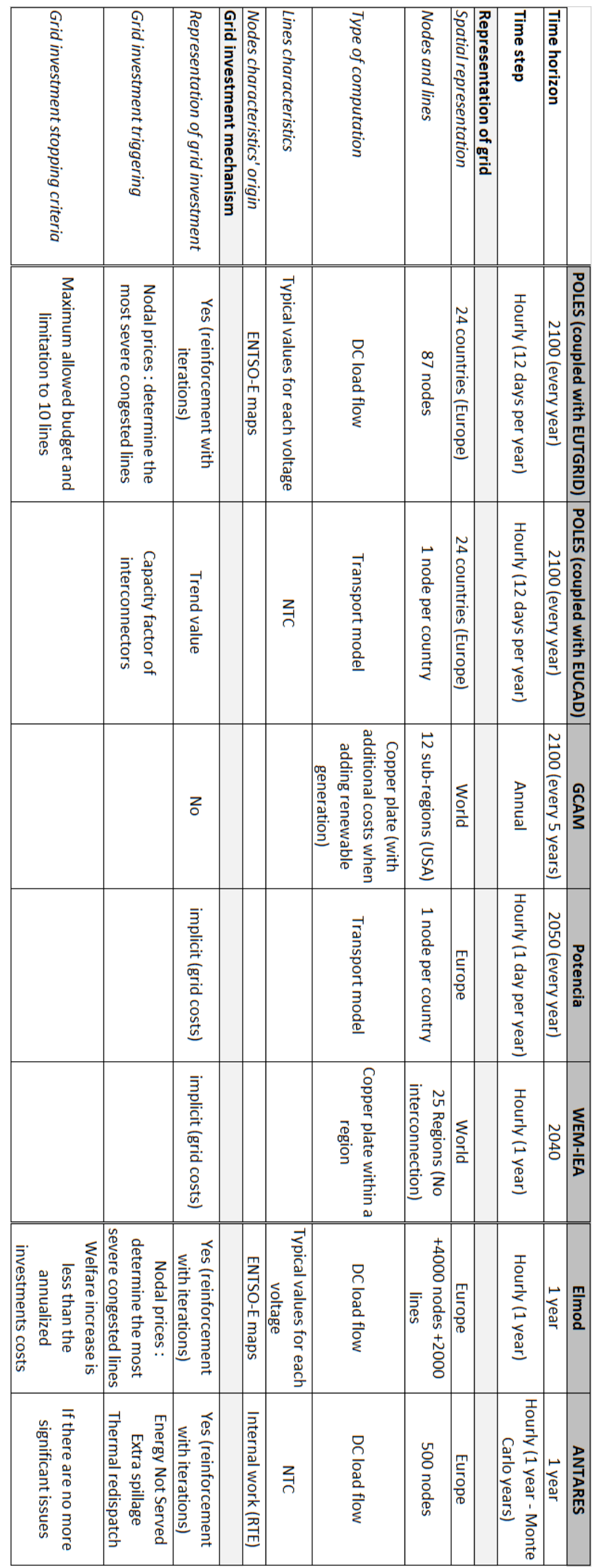




\section{Annex 2: EUTGRID, model description - equations}

EUTGRID is a unit and commitment and dispatch which minimizes the total costs of operations of the power system on a 24 hour basis as shown in equation 1:

$$
\begin{aligned}
\text { TotCost }=\sum_{\text {Cluster }} & \sum_{t=1}^{24}(\text { SocioEcoCost }(\text { Cluster }) * \text { UnservedLoad }(\text { Cluster }, t) \\
& +\sum_{\begin{array}{c}
\text { DispTech } \in \text { Technologies } \\
\text { s.t.Pmax }(\text { Cluster }, \text { DispTech })>0
\end{array}}(\text { VarCost }(\text { Cluster }, \text { DispTech }) \\
& * P(\text { Cluster , Disptech }, t)+\text { Ramping Cost }(\text { Cluster }, \text { DispTech }) \\
& \left.\left.* R(\text { Cluster, DispTech }, t)^{2}\right)\right)
\end{aligned}
$$

Where

- SocioEcoCost(Cluster) is the social cost of unserved load in a Cluster [\$/MWh]

- UnservedLoad(Cluster, $t$ ) is the load that could not be met and which is very expensive [MWh]

- $\operatorname{VarCost}($ Cluster, DispTech) is the variable costs of dispatchable technologies [\$/MWh]

- $P($ Cluster, Disptech, $t)$ is the power from dispatchable technologies [MWh]

- RampingCost(Cluster,DispTech) is the ramping cost for dispatchable technologies $\left[\$ / \mathrm{MW}^{2}\right]$

- $R($ Cluster, DispTech, $t)$ is the ramping value for dispatchable technologies at time $t$ for each Cluster [MW]

This minimization is subject to constraints and the first ones correspond to the "DC-load flow".

$$
\begin{gathered}
\sum_{\text {Disptech }} P\left(\text { Cluster }_{i}, \text { Disptech }, t\right) \\
\left.=D\left(\text { Cluster }_{i}, t\right)+\sum_{j}\left(\text { Fac }_{j} \text { Cluster }_{i}, \text { Cluster }_{j}, t\right)+F d c\left(\text { Cluster }_{i}, \text { Cluster }_{j}, t\right)\right) \\
\text { Fac }\left(\text { Cluster }_{i}, \text { Cluster }_{j}, t\right)=S_{\text {Base }} * B_{i, j} *\left(\theta_{i}(t)-\theta_{j}(t)\right) \\
\text { Fac }\left(\text { Cluster }_{i}, \text { Cluster }_{j}, t\right) \leq \text { Facmax }_{i, j}
\end{gathered}
$$




$$
\begin{aligned}
\text { Fdc } \left._{\left(\text {Cluster }_{i}, \text { Cluster }_{j}, t\right.}\right) & \leq \text { Fdcmax }_{i, j} \\
\theta_{\text {ref }}\left(\text { Cluster }_{k}, t\right) & =0
\end{aligned}
$$

Where

- $P\left(\right.$ Cluster $_{i}$, Disptech,$\left.t\right)$ is the generation at cluster $i$ [MWh]

- $D\left(\right.$ Cluster $\left._{i}, t\right)$ is the demand at cluster $i[\mathrm{MWh}]$

- $F a c\left(\right.$ Cluster $_{i}$, Cluster $\left._{j}, t\right)$ and $F d c\left(\right.$ Cluster $_{i}$, Cluster $\left._{j}, t\right)$ are the flows within the AC or the DC lines between cluster $i$ and cluster $j$ [MWh]

- $B_{i, j}$ is the susceptance of the line between cluster $i$ and cluster $j[\mathrm{pu}]$

- $\theta_{i}(t)$ is the angle at cluster $i[\mathrm{rad}]$

- $\theta_{\text {ref }}\left(\right.$ Cluster $\left._{k}, t\right)$ is arbitrarily set to zero in order to be able to the solve the system of equations.

- $S_{\text {Base }}$ is the base power set 100 [MVA]

- $\operatorname{Facmax}_{i, j}, \operatorname{Fdcmax}_{i, j}$ is the maximum capacity of the line between cluster $i$ and cluster $j$ [MW]

It is important to note that equation (1) describes Kirchhoff's first law which states that at each node, the sum of power flows is equal to zero and equation (2) is the resulting simplification for DC load flow. Equations (3-5) are constraints for the system. ${ }^{12}$

Other constraints such as the ramping capabilities or maximum production are also taken into account.

\footnotetext{
${ }^{12}$ HVDC lines works differently: their power flow can be fully controlled.
} 


\section{Annex 3: EUTGRID validation for 2010 - 2030}

The coupling of POLES and EUTGRID has been validated by running the transmission grid capacity module from 2012 until 2030 for two different scenarios which are described in section 3 ("Ref-Grid" and "Clim-Grid"). From ENTSO-E's report (ENTSO-E 2014a) and as described in section 2.2.3, the investments decided by European Transmission System Operators (TSOs) can be found and compared to EUTGRID's results.

These investments are gathered in Table 2.

\begin{tabular}{|c|c|c|c|c|}
\hline & ENTSO-E & "Ref - Grid" scenario & "Clim - Grid" scenario \\
\hline & & $2010-2030$ & $2010-2030$ & $2010-2030$ \\
\hline \multicolumn{2}{|r|}{ Production VREs [\%] } & & {$[5 \% ; 14 \%]$} & {$[5 \% ; 22 \%]$} \\
\hline \multirow{5}{*}{ 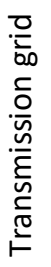 } & HVAC added [GW] & 202 & 76 & 65 \\
\hline & HVDC added [GW] & 42 & 32 & 46 \\
\hline & Line length added $[000 \mathrm{~km}]$ & 61 & 20 & 23 \\
\hline & Grid added [TWkm] & 97 & 45 & 47 \\
\hline & Total grid investment [b\$] & $\begin{array}{l}150 \text { (ENTSO-E evaluation) } \\
180 \text { (EUTGRID evaluation) }\end{array}$ & 78 & 89 \\
\hline
\end{tabular}

Table 2- Transmission grid investments for 2010-2030 based on ENTSO-E data and EUTGRID simulations

It can be noted that for all the indicators chosen, the investments decided by ENTSO-E are above the ones found by EUTGRID for each scenario. For example, European TSOs install more HVAC and HVDC capacities (202GW and 42GW) and it connects more regions (61000 $\mathrm{km}$ of lines are added) than for EUTGRID. Indeed, EUTGRID installs at most $65 \mathrm{GW}$ of HVAC and 46 HVDC which result in $47000 \mathrm{~km}$ of lines added.

As a result, the total investment for ENTSO-E's transmission planning reaches $150 \mathrm{~b} \$$ according to its report (EUTGRID evaluated these ENTSO-E's investments to 180b\$). This value can be compared to EUTGRID's total grid investment of $89 \mathrm{~b} \$(-40 \%)$. This large difference can be explained by different factors: first, the TYNDP report is based on detailed insights of the transmission grid. Indeed, TSOs know the actual state of the transmission grid and also the future location of VREs capacities. As a result, they already have first technical and economic studies to evaluate the reinforcements and the extension of their transmission grid. Hence, these 
studies take into account the grid reality and also social acceptance. EUTGRID does not have this knowledge and it can decide to extent the grid in a region where it is actually not possible.

ENTSO-E also maintained an update of the projects TYNDP 2014 and this report showed that $3 \%$ of the projects are cancelled, $15 \%$ are delayed and 15\% are rescheduled (ENTSO-E 2015) . According to the table of planning, $22 \%$ of the projects are either cancelled, rescheduled during the period 2025-2030 or after 2030. These projects are the most subject to modifications as more precise technical and economic studies will be made. Finally, these projects represent at most 33b\$ which let $117 \mathrm{~b} \$$ of transmission grid investments during the period 2010-2030.

As EUTGRID cannot consider cancellations, delays or rescheduling, these investments of $117 \mathrm{~b} \$$ for ENTSO-E can be compared with EUTGRID's own investments of 89b\$ (-24\%). 


\section{Acknowledgements}

This work was funded by a grant from the region Auvergne Rhône-Alpes through the program

ARC 4 - Energies.

\section{References}

Anderski, Thomas, Yvonne Surmann, Simone Stemmer, Nathalie Grisey, Eric Momot, AnneClaire Leger, Brahim Bretaoui, and Peter Van Roy. 2014. 'European Cluster Model of the Pan-European Transmission Grid'. D 2.2. e-HIGHWAY 2050. http://www.ehighway2050.eu/fileadmin/documents/Results/D2_2_European_cluster_model_of_the _Pan-European_transmission_grid_20072015.pdf.

Bett, Philip E., and Hazel E. Thornton. 2016. 'The Climatological Relationships between Wind and Solar Energy Supply in Britain'. Renewable Energy 87 (March): 96-110. https://doi.org/10.1016/j.renene.2015.10.006.

Bruninx, Kenneth, Dragana Orlic, Dries Couckuyt, Nathalie Grisey, Brahim Bretaoui, Thomas Anderski, Yvonne Surmann, et al. 2014. 'Data Sets of Scenarios for 2050'. eHIGHWAY 2050.

Commission de régulation de l'énergie. 2013. Délibération Du 3 Avril 2013 Portant Décision Relative Aux Tarifs d'utilisation d'un Réseau Public d'électricité Dans Le Domaine de Tension HTB.

Commission renewable energy. 2017. 'Commission Renewable Energy Progress Report - 4th Version'.

https://ec.europa.eu/energy/sites/ener/files/documents/report_of_the_commission_exp ert_group_on_electricity_interconnection_targets.pdf.

Couckut, Dries, Dragana Orlic, Kenneth Bruninx, Alessandro Zani, Anne-Claire Leger, Eric Momot, and Nathalie Grisey. 2015. 'System Simulations Analysis and Overlay-Grid Development'. e-HIGHWAY 2050.

Criqui, P., and S. Mima. 2012. 'European Climate_energy Security Nexus: A Model Based Scenario Analysis'. Energy Policy 41 (February): 827-42. https://doi.org/10.1016/j.enpol.2011.11.061.

Criqui, P., S. Mima, P. Menanteau, and A. Kitous. 2015. 'Mitigation Strategies and Energy Technology Learning: An Assessment with the POLES Model'. Technological Forecasting and Social Change 90 (January): 119-36. https://doi.org/10.1016/j.techfore.2014.05.005.

Després, Jacques. 2015. 'Modelling the Long-Term Deployement of Electricity Storage in the Global Energy System'. Grenoble Alpes. http://www.theses.fr/2015GREAT073.

Després, Jacques, Nouredine Hadjsaid, Patrick Criqui, and Isabelle Noirot. 2015. 'Modelling the Impacts of Variable Renewable Sources on the Power Sector: Reconsidering the Typology of Energy Modelling Tools'. Energy 80 (February): 486-95. https://doi.org/10.1016/j.energy.2014.12.005.

Després, Jacques, Silvana Mima, Alban Kitous, Patrick Criqui, Nouredine Hadjsaid, and Isabelle Noirot. 2017. 'Storage as a Flexibility Option in Power Systems with High Shares of Variable Renewable Energy Sources: A POLES-Based Analysis'. Energy Economics 64 (Supplement C): 638-50. https://doi.org/10.1016/j.eneco.2016.03.006.

Dietrich, Kristin, Uwe Hennemeier, Sebastian Hetzel, Till Jeske, Florian Leuthold, Ina Rumiantseva, Holger Rummel, Swen Sommer, Christer Sternberg, and Christian Vith. 2005. 'Nodal Pricing in the German Electricity Sector-A Welfare Economics 
Analysis, with Particular Reference to Implementing Offshore Wind Capacities. Final Report of the Study Project:"More Wind?". Chair of Energy Economics and Public Sector Management at Dresden University of Technology'. Working Paper WPEM08, Chair of Energy Economics and Public Sector Management, Dresden University of Technology, Dresden, Germany. https://tu-

dresden.de/die_tu_dresden/fakultaeten/fakultaet_wirtschaftswissenschaften/bwl/ee2/da teien/ordner_publikationen/wp_ge_08_dietrich_hennemeier_hetzel_et\%20al_nodal_pr icing_germany.pdf.

Doquet, M., R. Gonzalez, S. Lepy, Eric Momot, and F. Verrier. 2008. 'A New Tool for Adequacy Reporting of Electric Systems: ANTARES'. In , C1-305.

E3MLab. 2017. 'The PRIMES Model'. http://147.102.23.135/e3mlab/PRIMES\%20Manual/The\%20PRIMES\%20MODEL\%2 02016-7.pdf.

Egerer, Jonas, Clemens Gerbaulet, Richard Ihlenburg, Friedrich Kunz, Benjamin Reinhard, Christian von Hirschhausen, Alexander Weber, and Jens Weibezahn. 2014.

'Electricity Sector Data for Policy-Relevant Modeling - Data Documentation and Applications to the German and European Electricity Markets'. Deutsches Institut für Wirtschaftsforschung.

Egerer, Jonas, Clemens Gerbaulet, and Casimir Lorenz. 2016. 'European Electricity Grid Infrastructure Expansion in a 2050 Context'. The Energy Journal 37 (01). https://doi.org/10.5547/01956574.37.SI3.jege.

e-Highway 2050. 2015. 'Grid Reinforcements Design for Long Term Transmission Planning in Europe'. 2015. http://www.gridinnovation-on-line.eu/Articles/Library/E-Highway2050-Grid-Reinforcements-Design-For-Long-Term-Transmission-Planning-InEurope.kl.

Enipedia. 2016. 'Portal:Power Plants'. 2016. http://enipedia.tudelft.nl/wiki/Portal:Power_Plants.

ENTSO-E. 2014a. '10-Year Network Development Plan 2014'. https://www.entsoe.eu/majorprojects/ten-year-network-development-plan/tyndp2014/Documents/TYNDP\%202014_FINAL.pdf. . 2014b. 'On-Line Application Portal for TYNDP 2014 Input Datasets'. 2014. https://www.entsoe.eu/publications/statistics/network-dataset/TYNDP-2014-inputdatasets/Pages/default.aspx.

. 2015. '2015 Monitoring Update of the TYNDP 2014'. ENTSO-E. https://www.entsoe.eu/Documents/TYNDP\%20documents/TYNDP\%202014/TYNDP $\% 202014 \% 20$ monitoring\%20update_statistics\%20and\%20table_FINAL.PDF.

Global Energy Observatory. 2016. 'Information on Global Energy Systems and Infrastructure'. 2016. http://globalenergyobservatory.org/.

Grisey, Nathalie. 2016. '[Projet e-Highway 2050] Modèle de clustering du réseau de transmission européen', 2 May 2016.

Hutcheon, Neil, and Janusz W. Bialek. 2013. 'Updated and Validated Power Flow Model of the Main Continental European Transmission Network'. In PowerTech (POWERTECH), 2013 IEEE Grenoble, 1-5. IEEE. http://ieeexplore.ieee.org/xpls/abs_all.jsp?arnumber=6652178.

IEA. 2016. 'World Energy Model Docummentation - 2016 Version'.

IRENA. 2017. 'Planning for the Renewable Future: Long-Term Modelling and Tools to Expand Variable Renewable Power in Emerging Economies'. http://www.irena.org/DocumentDownloads/Publications/IRENA_Planning_for_the_R enewable_Future_2017.pdf. 
. 2018. 'Renewable Energy Prospects for the European Union'. http://irena.org//media/Files/IRENA/Agency/Publication/2018/Jan/IRENA_REmap_EU_preview_201 8.pdf.

Jeske, Till, Florian Leuthold, Hannes Weigt, and Christian von Hirschhausen. 2007. 'When the Wind Blows Over Europe: A Simulation Analysis and the Impact of Grid Extensions'. In IDEI/Bruegel Conference Regulation, Competition and Investment in Network Industries.

http://www.academia.edu/download/42237818/1842_When_the_Wind_Blows_over_ Europe.pdf.

Kunz, Friedrich. 2013. 'Improving Congestion Management: How to Facilitate the Integration of Renewable Generation in Germany'. The Energy Journal 34 (4). https://doi.org/10.5547/01956574.34.4.4.

Leuthold, Florian U., Hannes Weigt, and Christian von Hirschhausen. 2012. 'A Large-Scale Spatial Optimization Model of the European Electricity Market'. Networks and Spatial Economics 12 (1): 75-107. https://doi.org/10.1007/s11067-010-9148-1.

Mantzos, Leonidas, Katerina Ciampi Stancova, and Institute for Prospective Technological Studies. 2016. POTEnCIA Model Description: Version 0.9. Luxembourg: Publications Office. http://bookshop.europa.eu/uri?target=EUB:NOTICE:LFNA27768:EN:HTML.

Manzo, Vincent. 2009. 'Traitement Des Congestions Dans Les Réseaux de Transport et Dans Un Environnement Dérégulé'. INSTITUT NATIONAL POLYTECHNIQUE DE GRENOBLE.

http://www.iaea.org/inis/collection/NCLCollectionStore/_Public/45/087/45087468.pdf

Nahmmacher, Paul, Eva Schmid, Lion Hirth, and Brigitte Knopf. 2014. 'Carpe Diem: A Novel Approach to Select Representative Days for Long-Term Power System Models with High Shares of Renewable Energy Sources'. http://papers.ssrn.com/sol3/papers.cfm?abstract_id=2537072.

Phillips, Drew. 2004. 'Nodal Pricing Basics'. Independent Electricity Market Operator. https://iesoqapublic.sharepoint.com/Documents/consult/mep/LMP_NodalBasics_2004jan14.pdf.

Pietzcker, Robert C., Falko Ueckerdt, Samuel Carrara, Harmen Sytze de Boer, Jacques Després, Shinichiro Fujimori, Nils Johnson, et al. 2017. 'System Integration of Wind and Solar Power in Integrated Assessment Models: A Cross-Model Evaluation of New Approaches'. Energy Economics 64 (Supplement C): 583-99. https://doi.org/10.1016/j.eneco.2016.11.018.

RTE. 2016. 'Schéma décennal de développement du réseau de transport d'électricité Synthèse de la consultation publique et Annexes'. http://www.rtefrance.com/sites/default/files/sddre_annexes.pdf.

Saha, Suranjana, Shrinivas Moorthi, Xingren Wu, Jiande Wang, Sudhir Nadiga, Patrick Tripp, David Behringer, et al. 2011. 'NCEP Climate Forecast System Version 2 (CFSv2) Selected Hourly Time-Series Products'. UCAR/NCAR - Research Data Archive. https://doi.org/10.5065/D6N877VB.

Schaber, Katrin. 2014. 'Integration of Variable Renewable Energies in the European Power System: A Model-Based Analysis of Transmission Grid Extensions and Energy Sector Coupling'. Technische Universität München.

Skånlund, Anders Berg, Arndt von Schemde, Berit Tennbakk, Guro Gravdehaug, and Roger Grøndahl. 2013. 'Loop Flows - Final Advice'. THEMA for European Commission.

Vafeas, A., T. Pagano, and E. Peirano. 2014. 'D3.1 : Technology Assessment from 2030 to 2050'. e-Highway 2050. http://www.e- 
highway2050.eu/fileadmin/documents/Results/D3_1_Technology_assessment_from_2 030_to_2050.pdf.

Van Beeck, Nicole. 2000. Classification of Energy Models. Tilburg University, Faculty of Economics and Business Administration.

Velte, Daniela, Edume Magro, and Izaskun Jiménez. 2010. 'ReRisk - Regions at Risk of Energy Poverty'.

Zhou, Q., and J.W. Bialek. 2005. 'Approximate Model of European Interconnected System as a Benchmark System to Study Effects of Cross-Border Trades'. IEEE Transactions on Power Systems 20 (2): 782-88. https://doi.org/10.1109/TPWRS.2005.846178.

Zhou, Qiong. 2003. 'Cross-Border Congestion Management in the Electricity Market'. Ph. D. thesis, Durham University. URL http://etheses. dur. ac. uk/1263. http://etheses.dur.ac.uk/1263/1/1263.pdf. 